\title{
A small supernumerary marker chromosome present in a Turner syndrome patient not derived from $X$ - or $Y$-chromosome: a case report
}

Frenny Sheth1, Elisabeth Ewers² ${ }^{2}$ Nadezda Kosyakova², Anja Weise ${ }^{2}$, Jayesh Sheth ${ }^{1}$, Manisha Desai ${ }^{1}$, Joris Andrieux ${ }^{3}$, Joris Vermeesch ${ }^{4}$, Ahmed B Hamid ${ }^{1}$, Monika Ziegler ${ }^{2}$ and Thomas Liehr*2

\author{
Address: ${ }^{1}$ Institute of Human Genetics, Foundation for Research In Genetics and Endocrinology [FRIGE], Jodhpur Gam Road, Satellite,

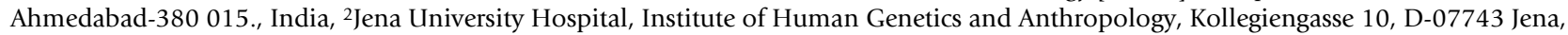 \\ Germany, ${ }^{3}$ Laboratory of Medical Genetics, Jeanne de Flandre Hospital CHRU de Lille, Lille Cedex, France and ${ }^{4}$ Center for Human Genetics, \\ K.U.Leuven, Herestraat 49, 3000 Leuven, Belgium \\ Email: Frenny Sheth - fshethad1@googlemail.com; Elisabeth Ewers - ewel@mti.uni-jena.de; Nadezda Kosyakova - kosna@mti.uni-jena.de; \\ Anja Weise - aweise@mti.uni-jena.de; Jayesh Sheth - fshethad1@googlemail.com; Manisha Desai - fshethad1@googlemail.com; \\ Joris Andrieux - joris.vermeesch@uz.kuleuven.ac.be; Joris Vermeesch - joris.vermeesch@uz.kuleuven.ac.be; Ahmed B Hamid - ahamid@mti.uni- \\ jena.de; Monika Ziegler - mzie@mti.uni-jena.de; Thomas Liehr* - i8lith@mti.uni-jena.de \\ * Corresponding author
}

Published: 12 November 2009

Molecular Cytogenetics 2009, 2:22 doi:10.1186/1755-8166-2-22
Received: 6 October 2009

Accepted: 12 November 2009

This article is available from: http://www.molecularcytogenetics.org/content/2/1/22

() 2009 Sheth et al; licensee BioMed Central Ltd.

This is an Open Access article distributed under the terms of the Creative Commons Attribution License (http://creativecommons.org/licenses/by/2.0), which permits unrestricted use, distribution, and reproduction in any medium, provided the original work is properly cited.

\begin{abstract}
Background: Small supernumerary marker chromosomes (SSMC) can be present in numerically abnormal karyotypes like in a 'Turner-syndrome karyotype' mos 45,X/46,X,+mar.

Results: Here we report the first case of an sSMC found in Turner syndrome karyotypes (sSMCT) derived from chromosome 14 in a Turner syndrome patient. According to cytogenetic and molecular cytogenetic characterization the karyotype was $46, \mathrm{X},+\operatorname{del}(\mathrm{I})(\mathrm{q} I \mathrm{I} . \mathrm{I})$. The present case is the third Turner syndrome case with an $\mathrm{SSMC}^{\top}$ not derived from the $\mathrm{X}$ - or the $\mathrm{Y}$-chromosome.
\end{abstract}

Conclusion: More comprehensive characterization of such $\mathrm{SSMC}^{\top}$ might identify them to be more frequent than only $\sim 0.6 \%$ in Turner syndrome cases according to available data.

\section{Background}

Small supernumerary marker chromosomes (sSMC) [1] can be observed in a numerically normal 'basic karyotype', but also in numerically abnormal one like in a 'Turner-syndrome karyotype' $\left(=\mathrm{sSMC}^{\mathrm{T}}\right)$. At present 528 such cases with an $\mathrm{sSMC}^{\mathrm{T}}$ are reported $[2,3]$. $\mathrm{sSMC}^{\mathrm{T}}$ are very rare in the common population $(1: 100000$ [2]) however, they can be observed 45 and even 60 times more frequent in infertile and developmentally and/or mentally retarded patients, respectively. The majority of $\operatorname{sSMC}^{\mathrm{T}}(\mathrm{X})$ form ring-chromosomes, while most $\operatorname{sSMC}^{\mathrm{T}}(\mathrm{Y})$ are inverted duplicated/isodicentric ones. When a mos $45, \mathrm{X} /$ $46, \mathrm{X}, \operatorname{der}(\mathrm{Y})$ or $45, \mathrm{X} / 46, \mathrm{XY}$ is characterized it is important to counsel the patient concerning a possibility of gonadoblastoma and a preventive removal of gonadal tissue. In this connection, the necessity to apply molecular approaches for detection of cryptic 45,X/46,XY mosaicism is discussed, as a direct relationship between percentage of cells exhibiting a 45,X karyotype and patients phenotype does not exist. Additionally, it is a well-known fact that in 
a karyotype of mos $45, \mathrm{X} / 46, \mathrm{X}, \mathrm{der}(\mathrm{X})$ it is important to test for the ability of the $\operatorname{der}(\mathrm{X})$ to be inactivated, i.e. to test for the presence of the XIST-gene [2].

Even though sSMCT derive in $>99 \%$ of the cases from one of the gonosomes, there are also two previous exceptional reports on $\mathrm{sSMC}^{\mathrm{T}}$ derived from one of the autosomes $[4,5]$.

Here we report the third case with an $\mathrm{sSMC}^{\mathrm{T}}$ originating not from a gonosome but the first one proven to be derived from chromosome 14 .

\section{Case presentation}

A ten year old girl was studied cytogenetically due to typical features of a Turner syndrome, i.e. short stature, webbing of neck, cubitus valgus, shield chest, congenital dislocation of hip, renal anomalies, clinodactyly, unilateral simian crease on right palm, acyanotic congenital heart disease and small patent ductus arteriosus.

\section{Results}

Cytogenetics revealed a karyotype $46, \mathrm{X},+$ mar in a patient with Turner syndrome. The sSMC ${ }^{\mathrm{T}}$ was acquired de novo, as parental chromosome analysis revealed. Array-CGH was done, however no clear imbalance apart from the lack of a second gonosome was observed (see also Fig. 1B). cenM-FISH identified the $\mathrm{SSMC}^{\mathrm{T}}$ as a derivative of chromosome 14 . In cenM-FISH the $\mathrm{SSMC}^{\mathrm{T}}$ did only show a signal for the probe D14/22Z1, but not for D22Z4 specific for the centromeric region of chromosome 22; thus, the sSMCT $^{\mathrm{T}}$ could be defined as a der(14). By subcenM-FISH and the array-CGH result was confirmed that the $\mathrm{sSMC}^{\mathrm{T}}$ did not contain euchromatic material and it could be defined as a del(14)(q11.1) (Fig. 1A).

\section{Discussion}

Here we report the third case of a patient with $\mathrm{sSMC}^{\mathrm{T}}$ not derived from a gonosome. It is the first such case where the sSMC was characterized in detail by molecular cytogenetics and which turned out to be a de novo derivative of chromosome 14. Previously one case with a der(20) [4] and a not further specified $\mathrm{sSMC}^{\mathrm{T}}$, however, proven to be not of gonosomal origin [5] were characterized. Overall, this is an interesting finding as neither chromosome 15 nor 22 were up to now identified as $\mathrm{SSMC}^{\mathrm{T}}$, even though these two chromosomes are most frequently involved in sSMC formation $[1,3]$. However, this might only be a bias due to only three known cases up to now. Furthermore, the exclusion of a uniparental disomy 14 would have been desirable; unfortunately no paternal material was available for that kind of study.

Among 3.400 reported sSMC cases studied for their chromosomal origin and subsequently reported [3], by now
528 cases with sSMCT ${ }^{\mathrm{T}}$ were found. Three of those sSMC were not of gonosomal origin, i.e. $0.6 \%$. However, the question is, if the percentage of this specific kind of $\mathrm{sSMC}^{\mathrm{T}}$ is not underestimated. Non-gonosomal $\mathrm{sSMC}^{\mathrm{T}}$ might be easily missed if they are not further characterized by molecular approaches.

In conclusion, a really comprehensive characterization of all sSMC by different probes, probe sets and approaches could enhance the detection rate of autosomal derived sSMCT $^{\mathrm{T}}$.

\section{Materials and methods Cytogenetics}

Metaphase chromosome preparations were obtained from PHA stimulated lymphocyte cultures according to standard procedures. Chromosome analysis was carried out applying GTG banding at a 600 band level according ISCN 2009 [6] in the patient (25 metaphases) and both parents (50 metaphases, each).

\section{Fluorescence in situ hybridization (FISH)}

FISH was performed as previously reported [7]. To characterize the sSMC first centromere specific multicolor FISH (cenM-FISH) and then subcentromere-specific M-FISH (subcenM-FISH) was performed; for details see [7]. The here applied probe RP11-324B11 in $14 \mathrm{q} 11.2$ is located at 19,886,099-19,886,646 Mb.

\section{Array-CGH}

Genomic DNA was extracted from peripheral blood lymphocytes using standard SDS-proteinase $\mathrm{K}$ extraction method [8]. DNA concentration was determined with NanoDrop ND-1000 spectrophotometer and software (NanoDrop Technologies, Berlin, Germany). Detection of gene copy number was performed by array-Comparative Genomic Hybridization (array-CGH) experiments following standard and manufacturer's recommendations using 44.000 oligo probes approximately spaced at $40-100 \mathrm{~kb}$ intervals across the genome (Human Genome CGH microarray 44B kit, Agilent $\left.{ }^{\mathrm{TM}}\right)$. Male genomic DNA (Promega $^{\mathrm{TM}}$ ) was used as reference in sex-match hybridizations which were analyzed with the CGH-analytics software v3.4 by applying Z-score segmentation algorithm with a window size of 10 points to identify chromosome aberrations. Analysis was performed with filter settings: 3point filter and 0.2 of variation.

\section{Consent section}

Written informed consent was obtained from the patient for publication of this case report and accompanying images. A copy of the written consent is available for review by the Editor-in-Chief of this journal. 
A

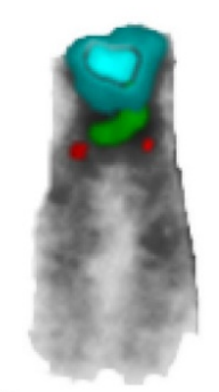

L

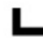

\section{midi54}

cep 14/22

RP11-324B11

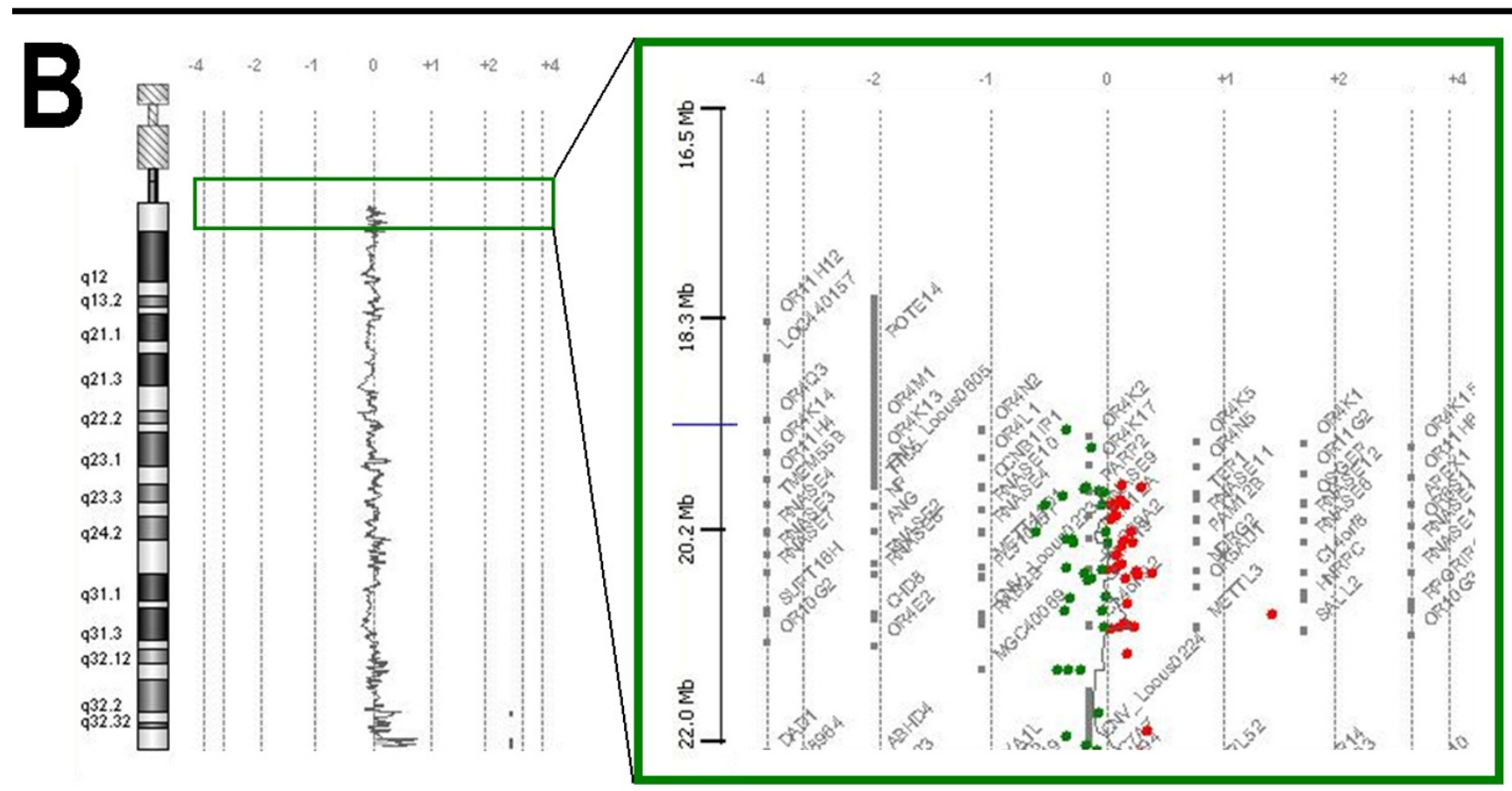

Figure I

A) SubcenM-FISH revealed the absence of euchromatic material on the sSMCT reported here. The sSMCT only showed one specific signal, each, for midi 54 (a probe specific for the acrocentric short arms) and the centromeric probe specific for chromosome 14 and 22 (cep 14/22). No specific signals were on the SSMC' for the centromere-near probe RPI I$324 \mathrm{BI}$ I in I4q II.2 and partial chromosome painting probe of chromosome I4 (the latter not depicted here). Thus, the sSMCT was a del(I4)(qII.I). B) After knowing the origin of the sSMC array-CGH was reanalyzed for I4q-proximal region. The first probe on Agilent 4x44K array location is on 19,365,05 I-19,365, IIO at I4q II.2. Thus, only genes from olfactory receptors ORIIHI2, OR4MI and OR4Q3, and POTEG and P704P may be involved in the marker chromosome. As it is a region known to be CNV polymorphic and the probe RPII-324BII at 19,886,099-19,886,646 is not present on the marker according to FISH array-CGH overall is to be considered as non-informative for this sSMC.

\section{Competing interests}

The authors declare that they have no competing interests.

\section{Authors' contributions}

FS, JS and MD performed the cytogenetic studies in the present case and collected the data relative to this case report. EE, NK, AW, $\mathrm{ABH}, \mathrm{MZ}$ and $\mathrm{TL}$ did the molecular cytogenetic analysis and interpretations. JA and JV were involved in the array-CGH analysis. TL drafted the paper and all authors contributed to the finalizing of the manuscript. 


\section{Acknowledgements}

Supported in parts by the DAAD (D07/00070 and fellowship for $A B H)$ and Prochance 2008 of the Friedrich Schiller University Jena 2100709I and

Dept of Biotechnology (DBT) - BT/PR9I I I/MED//2/337/2007, India.

\section{References}

I. Liehr T, Claussen $U$, Starke H: Small supernumerary marker chromosomes (sSMC) in humans. Cytogenet Genome Res 2004, I07(I-2):55-67.

2. Liehr T, Mrasek K, Hinreiner S, Reich D, Ewers E, Bartels I, Seidel J, Manoulakis E, Petersen M, Polityko A, Dufke A, lourov I, Trifonov V, Vermeesch J, Weise A: Small supernumerary marker chromosomes (sSMC) in patients with a karyotype $45, X / 46, X,+$ mar - 17 new cases and a review of the literature. Sex Dev 2007, I(6):353-362

3. Liehr T: sSMC homepage. 2009 [http://www.med.uni-jena.de/fish/ sSMC/OOSTART.htm].

4. Gray BA, Bent-Williams A, Wolff DJ, Zori RT: A non-sex chromosome marker in a patient with an atypical Ullrich-Turner phenotype and mosaicism of 46,X,mar/46,XX. Clin Genet 200I, 60(I):73-76.

5. Wiktor A, Van Dyke DL: FISH analysis helps identify low-level mosaicism in Ullrich-Turner syndrome patients. Genet Med 2004, 6(3): 132-135.

6. Shaffer L, Slovak ML, Campbell LJ, eds: ISCN 2009, an international system for human cytogenetic nomenclature (2009). $S$ Karger, Basel 2009.

7. Liehr T, Mrasek K, Weise A, Dufke A, Rodríguez L, Martínez Guardia N, Sanchís A, Vermeesch JR, Ramel C, Polityko A, Haas OA, Anderson J, Claussen U, von Eggeling F, Starke H: Small supernumerary marker chromosomes-progress towards a genotype-phenotype correlation. Cytogenet Genome Res 2006, I I 2(I-2):23-34.

8. Old JM, Ludlam CA: Antenatal diagnosis. Baillieres Clin Haematol | $991,4(2): 39 \mid-428$.

Publish with Biomed Central and every scientist can read your work free of charge

"BioMed Central will be the most significant development for disseminating the results of biomedical research in our lifetime."

Sir Paul Nurse, Cancer Research UK

Your research papers will be:

- available free of charge to the entire biomedical community

- peer reviewed and published immediately upon acceptance

- cited in PubMed and archived on PubMed Central

- yours - you keep the copyright

Submit your manuscript here:

http://www.biomedcentral.com/info/publishing_adv.asp
BiolMedcentral 